\title{
THE CEREBRAL GANGLIA OF THE EMBRYO OF RANA PIPIENS
}

\author{
F. L. LANDACRE AND MARIE F. MCLELLAN
}

From the Zoological Laboratory of the Ohio State University

ELEVEN FIGURES

CONTENTS

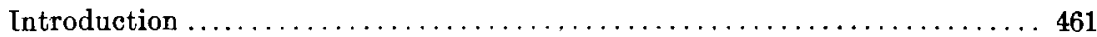

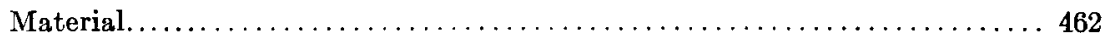

The trigemino-facial complex............................. 462

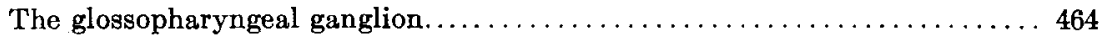

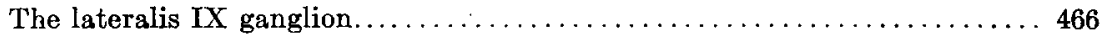

The vagus ganglia................................... 467

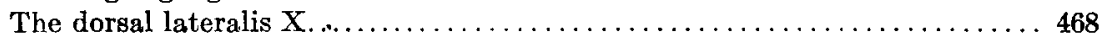

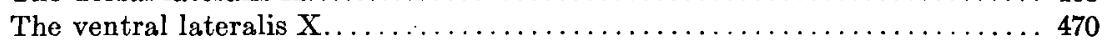

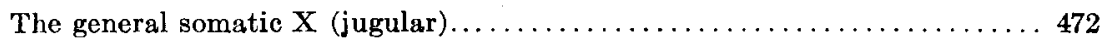

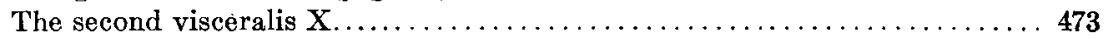

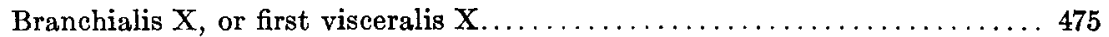

Summary and discussion................................ 477

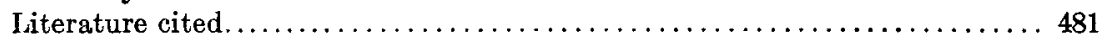

\section{INTRODUCTION}

A description of the cerebral ganglia of the frog embryo is undertaken as a preliminary to the study of the mode of origin of these ganglia.

This might seem superfluous in view of Strong's ('95) excellent work on the same subject but Strong's work was pioneer in nature and since it was published there have appeared a number of excellent papers on the cerebral nerves and ganglia in Amphibia. particularly those of Coghill ('02) and Norris ('08) in addition to numerous papers on other Ichthyopsida. While most of these papers confirm in general the analysis established by Strong. particularly for the composition of the trigemino-facial complex. there are certain features in the composition of the glossopharyngo- 
vagal complex of ganglia that are not as clear as could be desired in Strong's work and do not show the resemblance to the type of composition of ganglia usually found in the Ichthyopsida.

Since the V and VII complex conforms so closely to the type for Ichthyopsida, one would naturally expect the IX and X complex to be equally true to type, because the V and VII is usually the more highly developed and almost invariably has its ganglionic components more closely fused than IX $+\mathrm{X}$ in any given stage. An examination of embryos younger than that plotted by Strong shows the IX $+\mathrm{X}$ ganglionic complex to be really much more typical and not so highly fused as shown on Strong's plot, thus enabling one to make a much more detailed analysis.

\section{MATERIAL}

The series of embryos from which two were selected for plotting consists of eighty-six stages taken from one lot of eggs of Rana pipiens. The first fifty-three stages were taken at intervals of two hours beginning six hours after laying. From the fiftythird stage up to the eighty-fifth the intervals were less regular, ranging from one and three-quarter hours to nine hours, the average being less than five hours.

Out of this series number seventy-two, $8 \mathrm{~mm}$. in length $\left(171 \frac{1}{2}\right.$ hours old) and number eighty-six were chosen for plotting. Number eighty-six is 135 hours older than number seventy-two, being $306 \frac{1}{2}$ hours old and $10 \mathrm{~mm}$. in length. In addition to this series, a $25 \mathrm{~mm}$. tadpole of Rana pipiens was studied and also a $35 \mathrm{~mm}$. series kindly loaned by Professor Herrick. Neither of these last two were plotted, but they were carefully compared with the 8 $\mathrm{mm}$. and $10 \mathrm{~mm}$. embryos plotted. Stage $35 \mathrm{~mm}$. seems to be similar in all essential respects to Strong's plot.

\section{THE TRIGEMINO-FACIAL COMPLEX}

In the trigemino-facial complex (fig. 1) one point only needs to be emphasized, namely, the distinctness of the profundus ganglion. This ganglion, which in earlier stages is much more isolated than in the $8 \mathrm{~mm}$. embryo, though not entirely distinct, occupies 
the dorsal and mesial portion of the ganglion. It extends ventrally as a distinct ganglionic mass about two-thirds of the total dorso-ventral diameter of the combined Gasserian and profundus. The ramus ophthalmicus $(O . V$., fig. 1$)$ seems at this time to come entirely from the profundus portion, though doubtless there are fibers in this ramus derived from the ventral portion or Gasserian ganglion also. This nerve evidently contains later, if not at this time, the representatives of both the ophthalmic $V$ and of the opththalmicus profundus of the ganoids. The distinctness of this ganglion confirms the position taken by Wilder $(92$, p. 172) and confirmed by Strong ('95, p. 173), that the ophthalmicus profundus nerve has fused with the ramus ophthalmicus $V$ and that probably in higher types the profundus ganglion is fused with the Gasserian.

The infra-orbital trunk arises from the ventral border of the Gasserian ganglion and immediately splits into the $r$. maxillaris and the r. mandibularis. Smaller twigs described by.Strong could not be positively identified. The apparent difference between the point of origin of nerves in this complex in the $8 \mathrm{~mm}$. tadpole as compared with Strong's description, is due to the fact that in the older tadpole the head becomes flat, thus altering the position of the origin of nerves.

Aside from the difference noted below, the ganglia and nerves of the $8 \mathrm{~mm}$. tadpole conform closely to the description of Strong, whose findings we confirm in every detail except that some of the more minute branches could not be located in our material. It should be noted here that Strong's nomenclature is followed throughout in this paper.

The most striking feature in the arrangement of the $\mathrm{V}+\mathrm{VII}$ complex is the dorso-ventral elongation as compared with similar stages in Ameiurus (Landacre '10) and Lepidosteus (Landacre '12). This is probably due to the fact that it is crowded between the eye and the ear so that the long axis of this ganglion as well as of IX $+\mathrm{X}$ lies at right angles to the long axis of the body. It will be noticed in figure 1 that the special visceral or gustatory portion of the geniculate ganglion could not be identified. This is in marked contrast to Lepidosteus at a similar stage of growth. 


\section{THE GLOSSOPHARYNGEAL GANGLION}

The visceral portion of the IX ganglion is quite distinct from the $\mathrm{X}$ (figs. 1, 2, 3 and 7). It lies ventral to the ear capsule, its anterior end reaching almost to the anterior border of the ear capsule. The ganglionic cells disappear posteriorly at the level of the middle of the capsule and the ganglion here dwindles into a fibrous root which arches around under and behind the capsule and at the level of its posterior end ascends to enter the medulla at the same level as that at which the roots of the $\mathrm{X}$ enter it. It was not possible in either the $8 \mathrm{~mm}$. or the $10 \mathrm{~mm}$. stages to identify a special visceral, or gustatory portion, in the visceral IX, although a more careful study of earlier stages leading up to these might enable one to identify it.

The anterior end of the ganglion at this stage abuts against the posterior end of the thymus gland which consists of a dense mass of lymphocytes, oval in shape and lying at the same level dorso-ventrally as the glossopharyngeal ganglion. In stages earlier than that figured (figs. 3, 7, T.G.) the ganglion overlaps the gland to a greater extent, usually lying on the dorsal surface of its posterior end. These relations are important because of the fact that in early stages it is difficult to distinguish between the gland and the ganglion histologically, and further, on account of the fact that the ramus lingualis of the IX lies on the outer (lateral) surface and the pharyngeal ramus lies on the inner (mesial) side of the gland.

At the level of the middle of the ear capsule and at the posterior border, situated sometimes on the dorsal portion of the root of the IX sometimes surrounding the root, is a small lateralis ganglion which we have designated the lateralis IX ganglion. This ganglion, so far as we know, has not hitherto been identified as a distinct lateralis ganglion in the frog. Strong, however ('95, p. 144), correctly homologizes the nerve arising from this ganglion (the supra-temporalis) with a lateral line nerve of the IX in fishes. This is undoubtedly correct, since the ganglion has a separate existence from early stages and is only accidentally and quite variously related to the lateral line ganglia of the $\mathrm{X}$. 
The exact relation of the various ganglia in the IX and $\mathrm{X}$ as figured in plots 1 and 2 to the ganglia shown in Strong's plot is not always easy to determine.

There can be little doubt, however, that the glossopharyngeal ganglion is identical with ganglion $C$ of Strong's plot which occupies the extreme anterior end of the IX and X complex. It is hard to conceive of the IX ganglion of our plot being combined with $\mathrm{X}$ so as not to bring the IX into the position occupied by ganglion $C$.

The appearance of the IX ganglion in plots 1 and 2 is strikingly similar to that of Menidia (Herrick '99), and of Ameiurus (Landacre '10) and Lepidosteus (Landacre '12) of approximately the same stage.

In the $8 \mathrm{~mm}$. stage there is only one nerve arising from the visceralis IX. This is the ramus lingualis of Strong and runs forward on the outer surface of the thymus gland. In the 10 $\mathrm{mm}$. stage (fig. 2) there are two rami arising from the anterior end of the ganglion, the larger one running down and forward on the outer surface of the thymus gland, the ramus lingualis, and a smaller, the ramus pharyngeus, which runs down and forward on the inner surface of the thymus gland. We have been able to detect no trace of the ramus communicans IX ad VII at this stage in either the $8 \mathrm{~mm}$. or $10 \mathrm{~mm}$. embryo.

In the $35 \mathrm{~mm}$. larva there are three nerves arising from the anterior end of the IX ganglion. Two of them, corresponding to the ramus pharyngeus and the $r$. lingualis of Strong's plot, undoubtedly arise from the cells of the ganglion, since the fibrous bundles disappear in the ganglion. The third nerve corresponding to the communicating nerve from IX to VII apparently does not arise from the ganglion but runs back on the dorsal surface of the ganglion without diminishing in size and passes into the $\mathrm{X}$ ganglionic complex. Its behavior in passing the visceral IX ganglion furnishes strong evidence that it is probably not visceral but purely cutaneous as Strong describes it.

Of the two visceral nerves, the ramus lingualis is much the larger. It arises from the anterior end of the ganglion and pursues a course downward and forward on the outer surface of the 
thymus gland. The ramus pharyngeus pursues a similar course downward and forward on the mesial surface of the thymus gland and is distributed to the roof of the pharynx. The ramus communicans IX ad VII leaves the dorsal surface of the IX ganglion at its anterior end and pursues a course forward and downward on the mesial surface of the thymus gland which it leaves finally and, swinging towards the middle line of the body, joins the hyomandibular VII at the posterior border of the eye capsule.

The root of visceral IX can be followed with ease on both the $8 \mathrm{~mm}$. and $10 \mathrm{~mm}$. larvae back to the point where it becomes fused with that of visceral $\mathrm{X}$ (figs. 1 and $2, R . I X$ ). At this point there is not sufficient difference between the fibers of various roots to enable us to follow them through the ganglion with absolute certainty. The apparent course is indicated in figures 1 and 2 and at the point of emergence from the $\mathrm{X}$ ganglion to enter the brain the arrangement with one exception agrees identically with the description of Strong. Strong describes five roots entering the brain from the $X$, but up to the $10 \mathrm{~mm}$. stage only four can be found. The fifth of Strong's nomenclature is a pure motor root and is probably in our plot combined with the fourth.

\section{THE LATERALIS IX GANGLION}

This is a small ganglion situated on the root of the IX nerve just posterior to and at the level of the middle of the ear capsule (figs. 1, 2, 5 and 9, L.IX). The position is somewhat variable. In its early stages it has no connection with the lateralis $\mathrm{X}$ ganglion. It does, however, in the later stages become fused more or less with either the dorsal lateralis or the ventral lateralis. Its relation with the root of IX is constant, always being in contact with it. It may lie dorsal, ventral, or posterior to this root, but its one constant relation is with the IX. The fact that in its earlier stages it is completely detached from $\mathrm{X}$ leaves little doubt that, while it later becomes fused with $\mathrm{X}$, it is really a lateralis IX ganglion and does not belong morphologically to $X$. The enormous size of the auditory capsule, resulting in crowding the root of the IX back till it joins the $\mathrm{X}$, and the large size of the lateralis $\mathrm{X}$ ganglion account for its later fusion with these ganglia. This 
ganglion is heavily pigmented like the lateralis ganglion on VII and $X$. As to its relation to the lateralis ganglion of Strong's plot, we are uncertain. As we shall show later, Strong has apparently overlooked one of the lateralis ganglia on $\mathrm{X}$ owing probably to the extent of the fusion of the IX $+\mathrm{X}$ complex. Since the lateralis IX may sometimes combine with the dorsal lateralis $\mathrm{X}$, which is probably ganglion $A$ of Strong's plot, and sometimes with the dorsal border of ventral lateralis $\mathrm{X}$, which seems to be absent as a distinct ganglion in Strong's plot, it probably corresponds to the ventral border of Strong's ganglion $A$. This ganglion is composed, however, as Strong states, of two distinct ganglionic masses, a general cutaneous, the 'jugular,' and a lateralis $\mathrm{X}$. If it unites permanently with ganglion $A$, it is with the dorsal lateralis $\mathrm{X}$.

There is one nerve arising from this ganglion. It is quite small and pursues in a general way the same course as the auricularis $\mathrm{X}$, being quite separate from it, however, throughout its whole course. It arises from the ventral and anterior end of the ganglion and runs forward around the border of the posterior end of the auditory capsule to reach the epidermis. It is applied very closely to the capsule and is, of course, displaced backwards by the later growth of the auditory capsule. This nerve corresponds to the ramus supratemporalis of Strong's plot. The root of this nerve is difficult to follow but seems to enter the brain along with the lateralis roots of $\mathrm{X}$. From the ganglion it follows a course dorsally and posteriorly along the dorsal surface of dorsal lateralis $\mathrm{X}$, where it seems to join the fibers of this ganglion (figs. 1 and 2).

\section{THE VAGUS GANGLIA}

The vagal ganglionic complex .consists of five more or less distinct ganglionic masses (figs. 1 and 2). With these is associated in position, as indicated in the preceding section, the lateralis IX ganglion. These five ganglia fall into three well defined groups. First, the most dorsal and proximal portion consists of two ganglia; the dorsal lateralis (D.L.X.) and the jugular or general somatic $(C u . X$.$) . Of these two, the dorsal lateralis is lateral in position$ and the jugular is mesial in position. They are of nearly equal 
length dorso-ventrally, but the jugular extends farthest forward and the dorsal lateralis farthest posteriorly.

The second group (figs. 1 and 2) consists of two ganglia, the ventral lateralis (V.L.X.) and the second division of visceral $\mathrm{X}$ $\left(G . V \cdot X^{2}\right)$. This second group lies directly ventral to the first group. In this second group the ventral lateralis is lateral and the visceral ganglion is mesial. These two ganglia are approximately equal in their dorso-ventral length but antero-posteriorly the visceral is broader.

The third group (figs. 1 and 2, G.V.X $X^{1}$ ) consists apparently of two branchial ganglia fused, since two branchial nerves arise from it, but is treated here as one ganglion. It occupies the same level dorso-ventrally as the second group, but in general shape is much like the IX ganglion. Its long axis, unlike the two preceding groups, is in the anterior posterior plane and at its posterior end it is fused with the second division of visceral $\mathrm{X}$.

THE DORSAL LATERALIS $\mathrm{X}$

This ganglion (figs. 1, 2, 6, 10 and 11), as mentioned above, occupies the lateral portion of the proximal division of $\mathrm{X}$. It is also the most dorsal portion of the ganglionic complex. It is somewhat elongated dorso-ventrally, not reaching so far forward as the jugular, but extending considerably posterior to any other portion of the $X$. It begins abruptly in a rounded anterior end and diminishes in size as one reads posteriorly, where the most dorsal of the rami laterales take their origin at the extreme posterior end of the ganglion. The ventral border of this ganglion is in contact in the later stages, but not in the earlier stages, with the dorsal portion of the ventral lateralis $X$. The resemblance of this ganglion to the lateralis $\mathrm{X}$ ganglion in Ameiurus and Lepidosteus (Landacre '10 and '12) at similar stages of growth is striking. The large size of its cells, its position, its clean-cut boundaries and the extension of its posterior border beyond the posterior limits of the remaining ganglia mark it at once as the same ganglion. Its position with reference to the jugular and visceral $\mathrm{X}$ is the same in all three embryos. 
The relation of this ganglion to the lateralis ganglion of Strong's plot is doubtful. Strong figures and describes apparently only one lateralis ganglion in the $\mathrm{X}$ and locates it in ganglion $\boldsymbol{A}$. If the dorsal lateralis of our plot corresponds to Strong's ganglion $A$, there seems to be no homologue of our ventral lateralis in Strong's plot. Our ventral lateralis ganglion is quite distinct in both $8 \mathrm{~mm}$. and $10 \mathrm{~mm}$. embryos but in later stages seems to become more closely fused with the dorsal lateralis $\mathrm{X}$. It is very difficult to determine the limits between the two ganglia in a $35 \mathrm{~mm}$. tadpole. In the $35 \mathrm{~mm}$. tadpole, where the general arrangement of the ganglia and nerves is quite similar to their arrangement in Strong's plot, the dorsal lateralis $\mathrm{X}$ is still the most dorsal and posterior portion of the complex.

Dorsal lateralis $X$ in both $8 \mathrm{~mm}$. and $10 \mathrm{~mm}$. embryos gives rise to one nerve. This nerve arises from the extreme posterior end of the ganglion and pursues a course directly backwards as in Lepidosteus, Menidia and Ameiurus. This nerve corresponds to the most posterior R. lateralis, (1) of Strong's plot, which curves round behind the auditory capsule before leaving the ganglion. It splits into two divisions as Strong indicates. Its mode of origin and the general position of the ganglion leave no doubt that it corresponds to the ramus lateralis of Ameiurus and Lepidosteus. It also corresponds to the ramus lateralis superior and its dorsal branch in Amblystoma (Coghill '02), 'and to the lateralis medialis et dorsalis of Amphiuma (Norris '08).

The root of this ganglion (figs. 1 and 2), which enters along with the root of the ventral lateralis ganglion and of lateralis IX, is the most anterior of the roots of $\mathbf{X}$ as figured in Strong's plot.

The sympathetic ganglia are discussed here briefly on account of the proximity of the ganglion sympatheticus cervicale of Strong's plot (Strong '95, plate 12, gang. sym.) to the proximal part of the $X$ complex. According to Gaupp ('96), there is no sympathetic ganglion in the adult frog occupying a position so close to the $\mathrm{X}$ as indicated in Strong's plot.

The adult frog has a sympathetic ganglion on the second spinal nerve, the sensory part of the first spinal nerve of the $10 \mathrm{~mm}$. embryo being absent in the adult. From this first sympathetic 
ganglion a sympathetic cord extends forward and enters the $\mathrm{X}$ complex, from which a second sympathetic nerve runs forward to unite with the trigemino-facial complex. The connection between the glossopharyngo-vagal ganglion, the so-called jugular of the adult, and the trigemino-facial is intracranial. In the $10 \mathrm{~mm}$. embryo there are sympathetic ganglia on both the first and second spinal nerves in the usual positions. The sympathetic ganglion on the first spinal nerve is quite small, as is also the sensory ganglion of this nerve. The sympathetic ganglion on the second spinal nerve is, on the contrary, quite large. This, as stated above, is the first sympathetic of the adult. A careful examination of our whole series of embryos reyeals no sympathetic ganglion in the region of the $\mathrm{X}$. In fact, up to our latest stage and even in a $35 \mathrm{~mm}$. embryo it is not possible to follow the sympathetic nerve from the second sympathetic into the $X$ as a continuous cord and we have been unable to follow with certainty the intracranial connection between $\mathrm{X}+\mathrm{IX}$ and V + VII ganglia.

These facts indicate that the sympathetic ganglion and cords are in a very immature condition in a $10 \mathrm{~mm}$. embryo and even in a $35 \mathrm{~mm}$. embryo are difficult to follow in detail.

In a $10 \mathrm{~mm}$. embryo the first spinal ganglion is situated 22 sections posterior to the posterior end of lateralis $\mathrm{X}$ and the second spinal ganglion is 43 sections posterior to this point, so that the first sympathetic ganglion of a $10 \mathrm{~mm}$. embryo which becomes the first ganglion sympatheticus cervicale is back of the posterior end of lateralis $X$, a distance equal to the total anterior posterior length of IX $+X$. The change from this condition to that figured by Strong, if he has correctly located this ganglion, can only be accounted for by the shifting backwards of the IX + $\mathrm{X}$ complex by the enlargement of the auditory vesicle.

THE VENTRAL I.ATERALIS $\mathrm{X}$

This ganglion (figs. 1, 2, 6, 10, V.L.X.) occupies, as indicated above, the lateral position in the most distal and ventral division of the second group of ganglia. It is elongated dorso-ventrally; at its dorsal border it is in contact, particularly in later stages, from $10 \mathrm{~mm}$. on, with the ventral end of dorsal lateralis $\mathrm{X}$ and 
sometimes with lateralis IX. The ventral border of the ganglion diminishes in size and finally gives rise to a lateral line nerve which passes out with a visceral nerve of the $X$.

The mesial border of the ganglion is more or less closely fused with the lateral surface of visceral $X$ but can always be distinguished from it by the larger size of its cells and by the fact that the cells are always heavily pigmented. The position of this ganglion in Strong's plot is difficult to determine. Our series is not complete from $10 \mathrm{~mm}$. to the $35 \mathrm{~mm}$. embryo. The ganglion seems to shift its position proximally and join the dorsal lateralis ganglion, although not completely, since there are lateralis cells distributed along the dorsal surface of the visceral ganglion in the $35 \mathrm{~mm}$. stage. It must be identified for the present, provisionally, in part, with the ganglion $A$ of Strong and in part with the general position of his ganglion $B^{1}$ and $B^{2}$, to which he does not attribute lateralis cells. The ganglion is not distinct in either Amblystoma or Amphiuma, although Norris ('08) shows in Amphiuma a rather sharp division between the portion of the ganglion from which his ramus medialis et dorsalis and that from which his ramus lateralis ventralis arises. The former probably corresponds to the dorsal lateralis ganglion of our plot and the latter to the ventral lateralis. One nerve arises from the ganglion. It springs from the extreme ventral end of the ganglion and corresponds to the ramus lateralis (5) of Strong's plot. It also corresponds to the ramus inferior ( $L i$.) of Amblystoma (Coghill '02) and to the ramus lateralis ventralis (Lat. V.) of Amphiuma (Norris '08).

In the embryo frog, as well as in Amblystoma and Amphiuma, this nerve passes out of the ganglion in conjunction with visceral fibers. This is not so evident in Strong's plot, although his Ramus visceralis does come out of the ganglionic complex at the same point but the two trunks are separated up to the ganglionic mass. The conditions in our embryos are quite similar to the plots of Coghill and Norris, where the lateralis and the visceralis trunks pursue a similar course for some distance; at least one of the visceral rami is closely associated with the lateralis ventralis. The root of the ventral lateralis $X$ passes dorsally to enter the brain with the roots of the dorsal lateralis $\mathrm{X}$ (figs. 1 and 2). 
THE GENERAL SOMATIC X (JUGULAR)

The somatic $\mathrm{X}$ ganglion (figs. 1, 2, 6, 10,Cu.X.) occupies the mesial position in the proximal mass, or first division of the $X$ ganglion. It is in the $8 \mathrm{~mm}$. and $10 \mathrm{~mm}$. embryos entirely outside the cavity in which the medulla lies. As the head becomes broader and the whole $\mathrm{X}$ complex assumes a position more horizontal, general somatic $\mathrm{X}$ comes to lie ventral to the dorsal lateralis $\mathrm{X}$ and also shifts its position somewhat more proximal so that. in a $35 \mathrm{~mm}$. embryo its anterior end is intracranial, the remainder of it lying in the jugular foramen. This shifting of position gives the ganglion the general position occupied by the jugular ganglion in some of the fishes, i.e., intracranial. It extends further forwards than the dorsal lateralis $\mathrm{X}$, but does not reach farther than the middle of that ganglion posteriorly. Its ventral border is usually in contact with visceral $\mathrm{X}$, while its lateral, and later its dorsal border, are in contact with the mesial surface of dorsal lateralis $X$. The cells of this ganglion are smaller than those of either lateralis $\mathrm{X}$ but not so closely packed as those of visceral $X$. The ganglion is quite large, much larger than the jugular at similar stages in Ameiurus or Lepidosteus.

There is little difficulty in locating this ganglion in Strong's plot. It represents a portion of his ganglion $A$. It is quite distinct in all stages of the embryo up to and including the 10 $\mathrm{mm}$. stage. The most conspicuous nerve arising from this ganglion is the ramus auricularis, (2) of Strong's plot. He figures it as a pure general cutaneous nerve. It seems to be such in the embryo, but arises from the $\mathrm{X}$ ganglion in both Amblystoma and Amphiuma as a mixed nerve containing both general cutaneous and lateralis fibers. Its point of origin from the jugular ganglion is so close to the dorsal lateralis that there may possibly be lateralis fibers in it. Strong's interpretation of it as a pure general somatic nerve seems to hold however for the embryos we have studied.

The ramus auricularis arises from the anterior border of the ganglion at about the middle of its dorso-ventral extent and arches forward and outward to curve around the posterior border of the auditory capsule. A comparison of figures 1 and 2 will show 
that the ramus auricularis $\mathrm{X}$ takes its origin from the jugular ganglion farther posterior in a $10 \mathrm{~mm}$. embryo than in the $8 \mathrm{~mm}$. stage. A careful examination of twenty series lying between the $8 \mathrm{~mm}$. and the $10 \mathrm{~mm}$. stages shows that in all but one of them the ramus auricularis arises as in the $8 \mathrm{~mm}$. stage In the $10 \mathrm{~mm}$. stage this nerve arises posterior to the fibrous bundle connecting the two ventral ganglia of $\mathbf{X}$ to the two dorsal ganglia. This fibrous bundle passes lateral to the jugular ganglion (figs. 6 and 10) and it is probable that it is the active factor in determining these relations, i.e., it may form anterior or posterior to the point of exit of the ramus auricularis from the jugular ganglion.

The differences between the fibers of different components is not sufficiently great to enable one, at this stage, to follow the general cutaneous fibers into all the nerve trunks figured by Strong. The size of the ganglion is entirely sufficient to furnish, in addition to the ramus auricularis, the rather large bundles running out in two of the branchial rami and the ramus communicans IX ad VII. In describing this last ramus attention was called to the fact that, while it enters the anterior end of the glossopharyngeal ganglion, it runs past that ganglion and follows the root of the IX to enter apparently the jugular. Questions concerning the composition of mixed nerves are not easily settled on the material of the age used in this paper. Fortunately most nerves, even when mixed in the adult and in later embryonic stages, are likely to be pure and arise separately from a distinct ganglionic mass if the proper stage is studied. This is true of the ramus auricularis, but is not true of the other rami arising from the jugular ganglion, so that our findings as far as they go confirm those of Strong with respect to the rami arising from this ganglion.

\section{THE SECOND VISCERALIS $X$}

This ganglion (figs. 1, 2, 6, 10, G.V.X. $X^{2}$ ) occupies the mesial portion of the distal division of the vagus complex. On its dorsal and proximal border it is in contact with the jugular and on its lateral, and later on its dorsal surface, it is in contact with the ventral lateralis. On its anterior border it is in contact with the 
branchial $\mathrm{X}$ (figs. 1 and 2, G.V.X. $X^{1}$ ). Its longest diameter, like all other members of the vagus complex except the jugular and branchial, is the dorso-ventral. It projects somewhat further caudad than the ventral lateralis but not so far as the dorsal lateralis.

The position of this ganglion in Strong's plot cannot be determined with certainty. The portion of the $\mathrm{X}$ complex from which the visceral rami arise is represented as a mesial projection attached to the main ganglionic mass at the level of the ganglion $B^{2}$. It is labelled 'ramus visceralis 3' but is described by Strong as containing ganglion cells. There seems no doubt that the ramus visceralis (3) of Strong's plot represents the apex of our visceral ganglion, but whether the proximal part of our visceral ganglion is represented by $B^{1}$ or $B^{2}$ of Strong's plot is uncertain. It is probably represented by $B^{1}$, since the rami branchiales seem, on his plot, to come from $B^{2}$. The comparison on this basis harmonizes the two plots, since in the earlier stages represented in our plot the branchial nerves come from the branchial ganglion. The relations in the $10 \mathrm{~mm}$. embryo plot are quite clear and barring the reduction in the number of branchial nerves are quite typical.

The visceral nerves arising from this ganglion emerge from its ventral apex. There are two chief divisions at this stage. The more ventral arises in conjunction with the ramus lateralis ventralis (L.X.V., figs. 1 and 2) and the other arises somewhat more proximally and pursues a course directly posterior. This last branch is undoubtedly the ramus intestinalis (figs. 1 and 2, $V . X$.). As to the composition of the first, the branch arising with the lateral line ramus, there is less certainty. It probably is not purely sensory, but contains a large motor ramus, (4) of Strong's plot. But there are certainly visceral fibers in it also, probably supplying the fourth gill. 
BRANCHIALIS $\mathrm{X}$, OR FIRST VISCERALIS $\mathrm{X}$

This ganglion (figs. 1, 2, 4, 8, G.V.X') stands in sharp contrast to the remaining portion of $\mathrm{X}$ both in its shape and in its position in the body. It resembles both in shape and position the glossopharyngeal ganglion. Its long axis is parallel to the long axis of the body. It lies under the auditory capsule like the IX and not behind it like the remainder of the $X$. Its general shape is that of an elongated S-shaped column of cells, free at its anterior border but attached at its posterior border to visceralis $\mathrm{X}^{2}$. This attachment occurs at the middle or upper third of the anterior surface of the visceralis $X$. The anterior end of this ganglion lies under the posterior end of the auditory vesicle. From its anterior end, where a branchial nerve arises, it gradually increases in size until it fuses at its posterior end with the visceral $\mathrm{X}^{2}$.

The position of this ganglion in Strong's plot is represented apparently by ganglion $B^{2}$. It is from this ganglion that the branchial nerves emerge in his plot and Strong's ganglion $C$ is undoubtedly the glossopharyngeal. The only question in doubt is whether branchial $\mathrm{X}$ also corresponds to a part of $B^{1}$. This seems improbable since $B^{1}$ is the only ganglion left on Strong's plot that could represent the visceral $X^{2}$. The extent to which the IX $+\mathrm{X}$ complex is elongated by the posterior extension of the auditory capsule makes it difficult to follow the shifting of the ganglia, since there is a stage between the time when the ganglia are distinct, as in our plots, and the time when fibrillated paths can be followed, in which it is very difficult to determine ganglionic boundaries and still more difficult to separate components among fibers.

An interesting question arises here as to the homology of the branchial ganglia in the frog with the branchial ganglia of Menidia, Lepidosteus and Ameiurus. In these types there are four more or less distinct branchial ganglia in the vagal complex. In Lepidosteus, which at a similar stage of development most closely resembles the $8 \mathrm{~mm}$. stage of the frog, only one branchial nerve, that for the second true gill, arises from the first branchial $\mathrm{X}$ ganglion. The remaining three arise from the ventral border 
of the general visceral ganglion, each branchial nerve arising from a ventral prolongation extending downwards towards the appropriate gill. The condition shown by Herrick ('99, text-fig. 5) gives the exact relation of these branchial ganglia in Lepidosteus and Ameiurus, with the exception that the branchial ganglia are a little larger and somewhat more detached than in Ameiurus and Lepidosteus and the general visceral portion seems to be smaller. In the frog there are only two large branchial nerves and they both arise from the same ganglion. This ganglion has the same appearance and morphological relations as Branchial $X^{1}$ of Lepidosteus (Landacre '12). The question arises whether the branchial ganglion of the frog represents the branchial $\mathrm{X}^{1}$ of Lepidosteus, Ameiurus and Menidia or whether it represents two or more branchial ganglia of these types fused. The question can be answered definitely only by careful study of the embryological development of the branchial ganglia and nerves. The condition in the ganoid (Landacre '12) indicates that branchial ganglia other than $\mathrm{X}^{1}$ are incorporated with the general visceral $X$, since these ganglia are much smaller than in Menidia and much less distinct. The behavior of the second branchial nerve arising from this ganglion, as will be shown later, indicates that the ganglion that we have called visceralis $\mathrm{X}^{2}$ really represents the general visceral $X$ of Lepidosteus plus one or more branchial ganglia and that the branchial ganglia of $\mathrm{X}$ (figs. 1 and 2, G.V.X $X^{1}$ ) represents principally branchialis $\mathrm{X}^{1}$ of Lepidosteus.

As mentioned above, there are two branchial nerves (figs. 1 and $2, B r . X^{1}$ and $\left.B r . X^{2}\right)$ arising from branchialis $\mathrm{X}$. These correspond to the rami branchialis (6) and (7) of Strong's plot. The anterior (6 of Strong's plot) arises from the extreme anterior end of the ganglion and pursues a course downward and forward to the gill. The second ( 7 of Strong's plot) arises toward the posterior end of the ganglion and runs downward and forward to the gill. This nerve on entering the ganglion, however, is not lost entirely among the ganglion cells, as is the first nerve, but pur sues a course backward on the under surface of branchial $\mathrm{X}$ until it reaches the anterior border of visceral $X$. It is, however, in its course diminished in size and it may be possible that some of 
its cells of origin lie in the posterior portion of branchial $X$. It is hardly probable that all of them lie in branchial $X$, so that until the embryological origin is worked out the problem of the exact morphology of branchial $\mathrm{X}^{1}$ will have to be left as indicated above, i.e., that a part of the cells from which the second branchial nerve ( 6 of Strong's plot) originates lie in the visceral ganglion and that the visceral ganglion represents the general visceral ganglion of such types as Menidia, Lepidosteus and Ameiurus, plus the representative, one or more, of branchial ganglia of these types.

\section{SUMMARY AND DISCUSSION}

1. The trigemino-facial complex of the frog in stages earlier than those studied by Strong corresponds in all essential details with his analysis except in the greater isolation of the profundus. This ganglion in earlier stages is much more isolated than in the earliest plot given in this paper, but even in that it stands out rather distinctly, indicating its definite character which is lost by incorporation with the Gasserian. In other respects we confirm Strong's account of the V + VII ganglia in the frog.

2. The glossopharyngo-vagal complex of ganglia, on the contrary, if taken in the $8 \mathrm{~mm}$. and $10 \mathrm{~mm}$. stages, shows a much greater degree of simplicity and isolation of its various components than indicated by Strong and furthermore it is much more typical as compared with such types as Menidia, Ameiurus and Lepidosteus.

3. The lateralis components in the glossopharyngo-vagal complex are represented by three more or less distinct ganglia. These are, (a) a lateralis IX situated on the root of the IX behind and at the level of the middle of the auditory vesicle dorso-ventrally; (b) two lateralis $\mathrm{X}$ ganglia situated on the lateral surface of the cutaneous and general visceral ganglia respectively. Of these two ganglia, the dorsal lateralis is proximal and the ventral lateralis distal. The dorsal lateralis lies lateral to the jugular, or general cutaneous $X$, and gives rise to one nerve trunk which immediately after leaving the ganglion splits, giving rise to the most posterior ramus of Strong's plot (dorsalis and medialis of 
Coghill and Norris). This ganglion resembles closely in form and position the lateralis $\mathrm{X}$ of Ameiurus and Lepidosteus in similar stages of development. It extends considerably posterior to any other ganglion and the nerve arises at the posterior attenuated extremity as in those types.

(c) The ventral lateralis $\mathrm{X}$ is the third of these ganglia. It is ventral to dorsal lateralis $\mathrm{X}$ in young embryos, but later, owing to the flattening of the head, becomes more lateral in position. It lies lateral to visceralis $\mathrm{X}^{2}$ in young embryos and later assumes a more dorsal position with reference to visceralis $\mathrm{X}^{2}$ and also becomes more closely fused with the dorsal lateralis $\mathrm{X}$. It gives rise to one nerve which emerges from the ventral apex of the ganglion (the most anterior lateral line ramus (5) of Strong's plot and the ramus lateralis ventralis of Coghill and Norris).

The presence of two lateral line ganglia on $\mathrm{X}$ suggests at once a homology with the condition in VII where there are two lateral line ganglia also. As to the distinctness of this ganglion up to and beyond the $10 \mathrm{~mm}$. stage there can be no doubt. Nor is it doubtful that it is a lateral line ganglion. The size of its cells, their heavy pigmentation and the isolation of the ganglion settles both these doubts. As to the homology with ventro-lateral VII, we are not willing to go farther at present than to gives it a name signifying its composition and position in the $\mathrm{X}$ complex. It gives rise to the same component as ventro-lateral VII, it occupies the same relative position, i.e., lateral to a visceral ganglion and in the distal portion of the complex as does ventro-lateral VII. Its nerve also runs out in conjunction with a branchial nerve. If it should prove to have a similar mode of origin to that ganglion there would seem to be no objection to homologizing them. No other fish or amphibian studied so far as we know has a distinct ventral lateralis ganglion. An examination of the reconstructions of Coghill ('02) and of Norris ('08) indicates that probably the same condition will be found in Urodeles, since the lateral line cells extend well down ventrally toward the origin of the ramus lateralis ventralis in both cases.

4. The jugular, or general somatic $X$, as in other Ichthyopsida above the Cyclostomes, is the only representative of its type in 
the IX $+\mathrm{X}$ complex. It is situated mesial to the dorso-lateral $X$ and is consequently proximal of the visceral $X$. It is very large in the tadpole, much larger than in the Lepidosteus and Ameiurus at the same stage of growth and is much farther away from the medulla. In the $35 \mathrm{~mm}$. tadpole, however, it migrates towards the medulla and lies partly, though not wholly, in the jugular foramen.

One nerve arises pure from this ganglion at this stage, the ramus auricularis; others arise also but run out in conjunction with other components and could not be accurately traced. So far as they could be followed their distribution agrees with Strong's description.

5. The visceral ganglia of the glossopharyngo-vagal complex lie in three well defined masses: (a) the glossopharyngeal; (b) the first or most anterior visceral, and (c) the second or most posterior visceral.

(a) The glossopharyngeal ganglion occupies a position ventral to the auditory capsule with its long axis parallel to that of the body. The root is long and curves around behind the auditory capsule to enter the medulla along with those of $X$. It seems to be a pure visceral ganglion, although a cutaneous ramus, r. communicans IX ad VII, passes out from the anterior end of the ganglion. Its fibers, however, can be traced past the ganglion and apparently enter jugular $X$, as described by Strong. It was not possible in the stages studied to recognize the special visceral or gustatory portion of this ganglion. Two nerves, the ramus pharyngeus and the ramus laryngeus, arise from the anterior end of this ganglion.

(b) The first visceral or branchial ganglion of $\mathrm{X}$ resembles in shape and position the glossopharyngeal. It lies under the posterior end of the auditory capsule with its long axis parallel to that of the-body. Its posterior end is not, like that of IX, continued into a fibrous root but joins the cell mass of the second visceral $\mathrm{X}$ near its middle region. Gustatory cells could not be recognized in this ganglion in the stages studied. Two large nerves arise from this ganglion, the branchial 6 and 7 of Strong's plot. 
The presence of two branchial nerves arising from this ganglion would suggest that it represented two branchial ganglia fused. However, there is some doubt as to whether the fibers of the second branchial nerve arise in this ganglion or partly in this ganglion and partly in the second visceral ganglion.

(c) The second visceral $\mathrm{X}$ ganglion, unlike the glossopharyngeal and the first visceral $X$, lies with its long axis at right angles to that of the body. It gives rise to two chief nerve trunks; one, the ramus intestinalis and a smaller ramus which probably contains branchial fibers. The question as to the exact position of the branchial ganglia in these two visceral ganglia cannot be definitely settled without further examination of earlier stages. A careful study of a close series of embryos will probably show definitely the number and position of the epibranchial placodes and their position in the visceral ganglia, thus determining the number of branchial ganglia in this complex and their location.

6. The failure to distinguish special visceral or gustatory ganglia in Rana in the stages studied is not to be interpreted to mean, of course, that they are absent or cannot be isolated. As mentioned in the introduction, this paper is preliminary to a study of the mode of origin of the cerebral ganglia in the frog. As a matter of fact, epibranchial placodes are present in the stages earlier than $8 \mathrm{~mm}$. and well defined and seem to behave much as they do in Ameiurus and Lepidosteus. It is hardly probable that they will be so distinct or can be followed to so late a stage as in Lepidosteus, since they are not recognizable in the $8 \mathrm{~mm}$. stage. Neither is it likely that the frog will furnish such definite evidence as to the character of placodal ganglia as did Ameiurus, since all nerves arising from the IX seem to contain both general visceral and special visceral fibers, whereas in Ameiurus they seem to contain only special visceral fibers.

7. The results of the present paper emphasize the immense importance of having access to a large number of stages taken at close intervals from the same lot of eggs, if one is to reach safe conclusions in regard to the composition and origin of cerebral ganglia. All ganglia, particularly those derived from the neural crest, in their early stages are more or less ill defined; following 
this stage in Lepidosteus, Ameiurus and the frog there is a stage when the ganglia are better defined, have clean cut boundaries and give rise to fibrillated nerves, usually well isolated from each other; following this stage the ganglia fuse together more or less, their nerve trunks combine and they must be isolated largely by the difference in size of their nerve fibers. Evidently the second stage is the one most favorable for determining the number and position of ganglionic components and this stage can be found only when the series is complete and taken at close intervals.

\section{LITERATURE CITED}

Coghild, G. E. 1902 The cranial nerves of Amblystoma tigrinum. Jour. Camp. Neur., vol. 12, no. 3 .

GaUPP, E. 1896 In A. Ecker's and R. Wiederscheim's Anatomie des Frosches. Braunschweig.

Herrick, C. J. 1894 The cranial nerves of Amblystoma. Jour. Comp. Neur., vol. 4.

1899 The cranial and first spinal nerves of Menidia. Jour. Comp. Neur., vol. 9, no. 3 .

Landacre, F. L. 1910 The origin of the cranial ganglia in Ameiurus. Jour. Comp. Neur., vol. 20.

1912 The epibranchial placodes of Lepidosteus osseus and their relation to the cerebral ganglion. Jour. Comp. Neur., vol. 22, no. 1.

Norris, H. W. 1908 The cranial nerves of Amphiuma means. Jour. Comp. Neur., vol. 15, no. 6 .

Strong, Oliver S. 1895 The cranial nerves of Amphibia. Jour. Morph., vol. 10 , no. 1 .

Wrider, H. H. 1892 Die Nasengend von Menopoma alleghanense und Amphiuma tridactylum nebst Bemerkungen über die Morphologie des $\mathrm{R}$. ophthalmicus profundus trigemini. Zool. Jahr., Abth. f. Anat. n. Ontog., Bd. 5, Heft. 2. 


\section{ABBREVIATIONS}

Aud. V., Auditory vesicle

Aud., Auditory ganglion

$A u$. $X$., Ramus auricularis $\mathrm{X}$.

$B r . X^{1}$, First ramus branchialis $\mathrm{X}$.

$B r . X^{2}$, Second ramus branchialis $\mathrm{X}$.

$B u$. VII., Ramus buccalis VII.

$B . V$., Blood vessel

$C u$. $X$., Cutaneous or general somatic (jugular) ganglion of $\mathbf{X}$.

D. $L . X$., Dorsal lateralis ganglion of $\mathrm{X}$.

D. L. VII., Dorso-lateral lateralis ganglion of VII.

Gass., Gasserian or general somatic ganglion of $\mathrm{V}$.

Gen., Geniculate or visceral ganglion of VII.

G. V. IX., Visceral (Glossopharyngeal) ganglion of IX.

G. V. $X^{1}$, First division of the visceral ganglia of $\mathrm{X}$; possibly equivalent to two branchial ganglia

G. V. $X^{2}$, Second division of the visceral ganglia of $\mathrm{X}$.

Hyo. VII., Hyomandibularis VII.

$L$. IX., Lateralis ganglion of IX.

$L . X$. V., Ventral ramus of the lateral line nerve of $\mathrm{X}=\mathrm{R}$. Iateralis (5) of

Strong's plot. Strong '95, plate 12

$L . X . D$., Dorsal ramus of the lateral line nerve of $\mathrm{X}=\mathrm{R}$. lateralis (1) of

Strong's plot. Strong '95, plate 12

Man. V., Ramus mandibularis V.

Max. V., Ramus maxillarus V.

Mes., Mesencephalon

No., Notochord

O. V., Ramus ophthalmicus $\mathrm{V}$.

O. S. VII., Ramus ophthalmicus superficialis VII.

Opt., Optic vesicle

Pal. VII., Ramus palantinus VII.

Prof., Profundus ganglion

R. V., Root of V.

R. L. IX., Lateral line root of IX.

R. IX., Root of IX.

$R$. $P . I X$., Ramus pharyngeus IX.

R. $X . V+C .$, Visceral + somatic roots of X.

R. L. $X$., Lateral line root of $X+$ IX.

R. X., Root of X.

S. T. X., Ramus supra-temporalis X.

T. G., Thymus gland

$V . L$. VII., Ventral lateral line ganglion of VII.

V. L. X., Ventral lateral line ganglion of $\mathrm{X}$.

$V . X$., Ramus visceralis $\mathrm{X}$. 


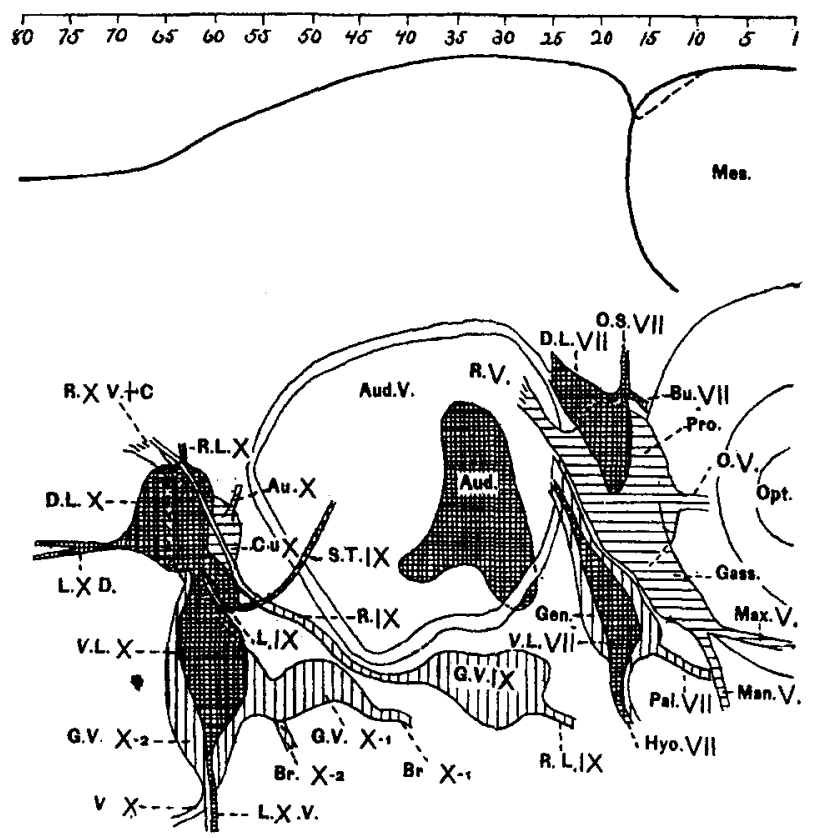

Fig. 1 A flat reconstruction of the V, VII, VIII, IX and X cerebral ganglia in Rana pipiens, $8 \mathrm{~mm}$. in length. The scale at the top of the figures indicates the position and number of sections $10 \mu$ in thickness over which the plot extends. General somatic ganglia are shown with horizontal lines, lateral line ganglia with cross hatched lines, and visceral ganglia with vertical lines: Special visceral or gustatory ganglia are not indicated, as their boundaries could not be determined in embryos of this age. $\ngtr 100$. 

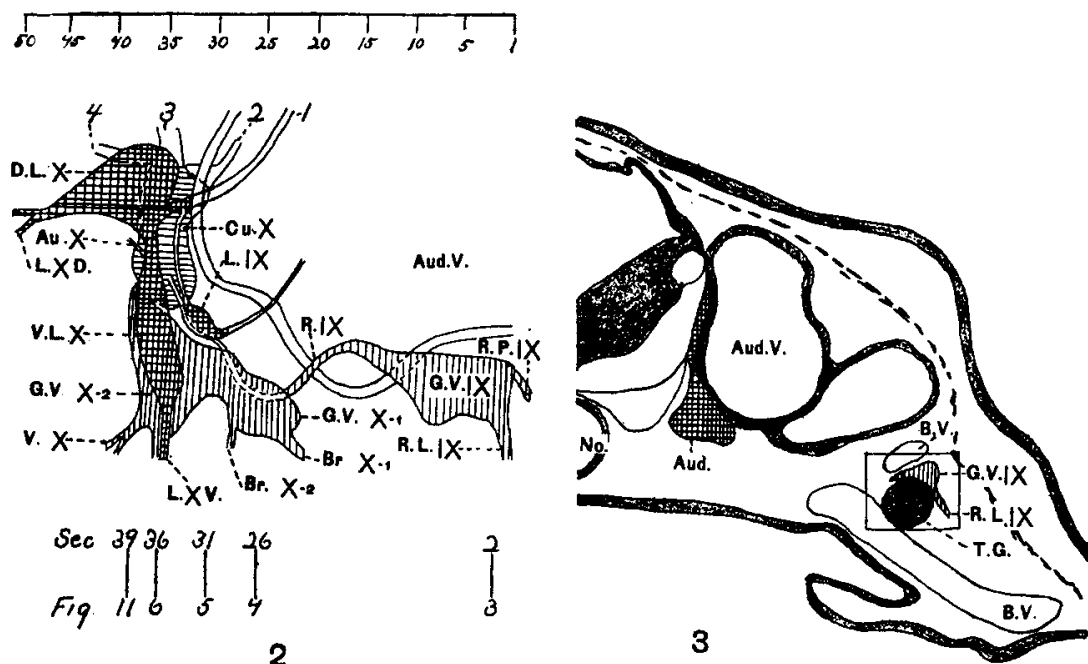

Fig. 2 A flat reconstruction of the IX and X cerebral ganglia of Rana pipiens $10 \mathrm{~mm}$. in length; shading as in figure 1. The scale at the top of the figure indicates number and position of sections $10 \mu$ in thickness over which the plot extends. The scale at the bottom of the plate indicates the number of the section and the number of the figure illustrated in succeeding plates. As in figure 1, the special visceral or gustatory ganglia are not indicated. 1,2,3,4 are the first four roots according to Strong's nomenclature (Strong '95, plate 12, fig. (a) and page 135). $\times 100$.

Fig. 3 A camera outline through the dorsal portion of the right side of the head of Rana pipiens, $10 \mathrm{~mm}$. in length. The section passes through the anterior end of the IX ganglion and the origin of the ramus laryngeus. The position of the section on figure 2 is indicated at the bottom of that figure (Sec. 2). The details of the area blocked out are shown on figure $7 . \times 50$. 

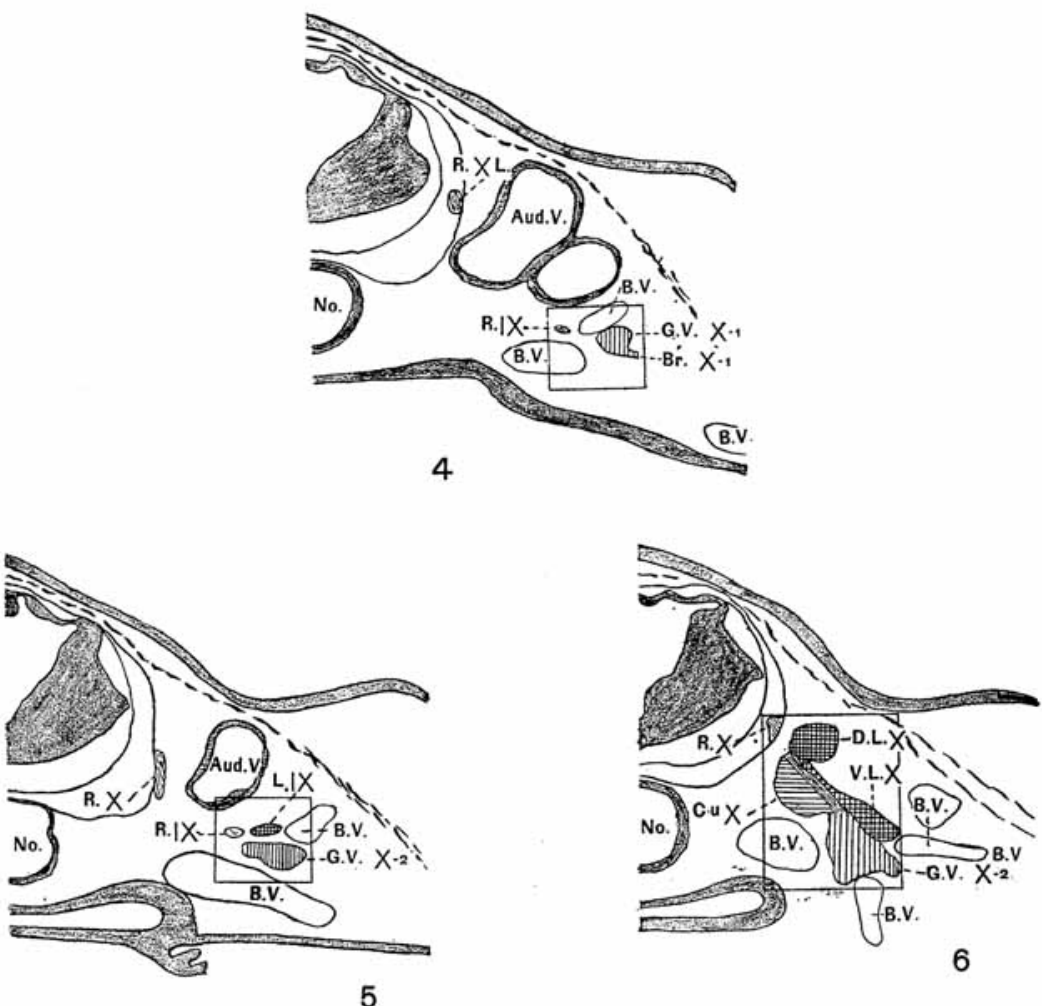

5

Fig. 4 A camera outline through the dorsal portion of the right side of the head of Rana pipiens, $10 \mathrm{~mm}$. in length. The section passes through the middle of the first portion of the visceral X ganglion (G.V.X. fig. 2) and the posterior portion of first branchial nerve $\left(B r . X^{1}\right)$ of that ganglion. The position of the section is indicated at the bottom of figure 2 (Sec. 26). The details of area blocked out are shown in figure $8 . \times 50$.

Fig. 5 A camera outline of the dorsal portion of the right side of the head of Rana pipiens, $10 \mathrm{~mm}$. in length. The section passes through the lateralis IX $(L . I X$.$) and the second visceral ganglion of \mathrm{X}\left(G . V . X^{2}\right)$. The position of this section is indicated at bottom of figure 2 (Sec. 31) and the details of the area blocked out are shown in figure $9 . \times 50$.

Fig. 6 A camera outline through the dorsal portion of the right side of the head of Rana pipiens; $10 \mathrm{~mm}$. in length. The section passes through the four posterior masses of the $\mathrm{X}$ ganglion. The position of this in figure 2 is indicated at the bottom of that figure (Sec. 36). The details of the area blocked out are given in figure 10. $\times 50$. 


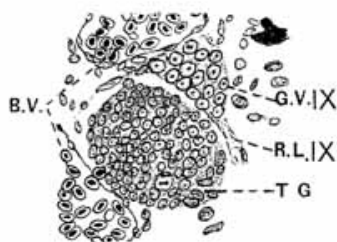

7

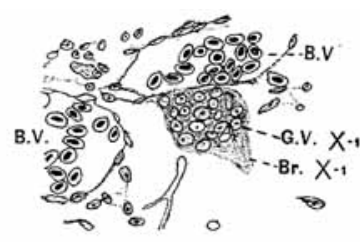

8
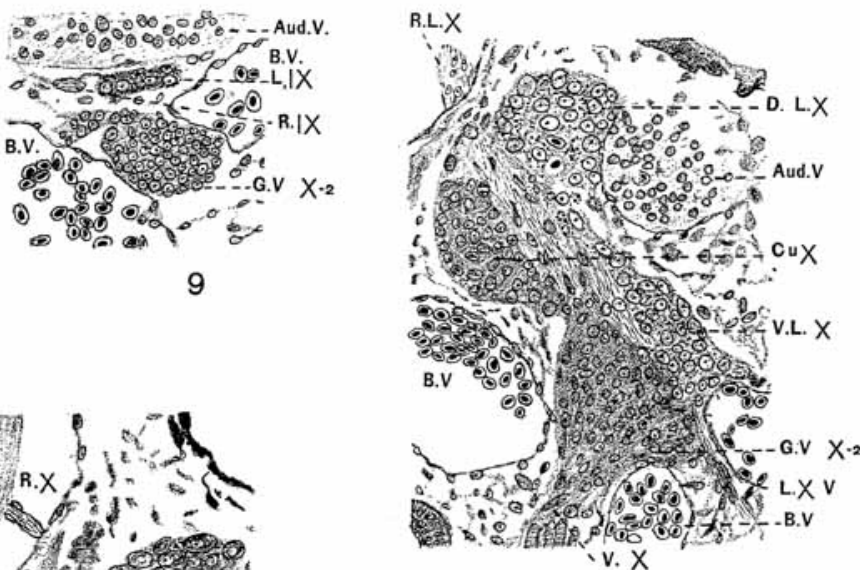

10

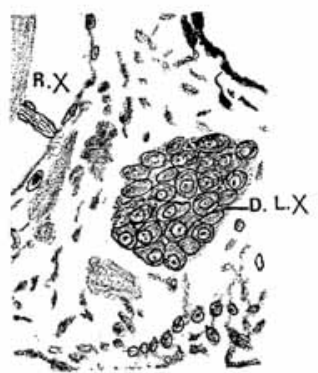

II

Fig. 7 Details of area blocked out in figure $3 . \times 200$.

Fig. 8 Details of area blocked out in figure $4 . \times 200$.

Fig. 9 Details of area blocked out in figure 5. $\times 200$.

Fig. 10 Details of area blocked out in figure $6 . \times 200$.

Fig. 11 Details of the lateralis $\mathrm{X}$ ganglion. The position of this section on figure 2 is shown at the bottom of that figure (Sec. 39). $\times 200$. 